\title{
Secondary Middle-ear Damages in Patients with Head and Neck Cancer after Radiotherapy
}

\section{Huong LD ${ }^{1}$, Nguyen $\mathrm{LP}^{1^{*}}$ and $\mathrm{Nguyen}^{\mathrm{H}} \mathrm{X}^{2}$}

${ }^{1}$ Department of Otorhinolaryngology, Military Medical 103 Hospital, Le Huu Trac Medical Pharmaceutical University, Vietnam ${ }^{2}$ Department of Pharmaceutical Sciences, College of Pharmacy, Mercer University, Atlanta, USA

\begin{abstract}
Objective: This study aimed to evaluate the relationship between radiotherapy and Eustachian tube dysfunction, and to investigate the efficacy of treatments by tympanostomy and grommet insertion.

Methods: Patients with head and neck cancer (148 patients) were treated by three-dimensional radiotherapy in the Center of Oncology and Nuclear Medicine, Military Medical 103 Hospital from February 2014 to April 2016. All patients underwent an ear examination (otoscopy), audiometry, and tympanometry test. Those who developed otitis media with effusion and tympanosclerosis were then treated by tympanostomy or myringotomy.

Results: The most common complication after the radiotherapy was found to be Eustachian tube dysfunction especially otitis media with effusion and tympanosclerosis. Thus, carefully examining and closely monitoring need to be performed to detect patients with secondary middle-ear damages, to successfully cure post-radiotherapy otitis media with effusion, and to minimize possible injury to the middle ear and Eustachian tube. Also, tympanostomy and myringotomy were reported to be the preferable treatments due to their simplicity, high quality, and patients compliance.

Conclusion: Eustachian tube dysfunction after radiotherapy treatment was the cause for otitis media with effusion and tympanosclerosis. Furthermore, tympanostomy and grommet insertion were convenient, efficient, and desirable treatments for secondary middle-ear damages in patients with head and neck cancer.
\end{abstract}

Keywords: Oncology; Nuclear medicine; Myringotomy; Neck cancer

Abbreviations: HNC: Head and Neck Cancer; OME: Otitis Media with Effusion; 3D: Three-Dimensional; PTA: Pure Tone Audiometry; RT: Radiotherapy

\section{Introduction}

Head and Neck Cancer (HNC) is one of the most popular and serious malignancies over the world for which radiotherapy (RT) is the mainstay of treatment. Radiotherapy including the definitive and postoperative adjuvant treatment has been favorably offered to approximately $75 \%$ HNC patients. Radiotherapy-associated toxicities and complications have been known to substantially reduce the quality of life of the patients, making them intolerant and unable to complete the treatment plan.

Otitis media with effusion (OME) has been known as a radiotherapy-related complication that leads to a reduced function of the Eustachian tube [1]. As reported in multiple otolaryngology literatures, post-irradiation eustachian dysfunction causes hearing loss at all frequencies. If not being timely detected and properly managed, this complication may progress to OME or tympanosclerosis [2]. At the Center of Oncology and Nuclear Medicine, Military Hospital 103, we have been operating three-dimensional (3D) conformal radiotherapy since 2013. This treatment has been recognized for its superiority in lowering the needed dose for conformal radiation, and targeted delivery into the diseased tissue without causing damages to the healthy vicinity $[3,4]$. In this study, we aimed to evaluate the relationship between radiotherapy and Eustachian tube dysfunction and to assess the efficacy of the treatments using tympanostosmy and grommet insertion.

\section{Materials and Methods}

\section{Patients}

This study was conducted on 148 patients who were diagnosed with
Head and Neck Cancer and treated by 3D conformal radiotherapy at the Center Of Oncology and Nuclear Medicine, Military Hospital 103 from February 2014 to April 2016. The patients were reported with no middle ear injury prior to the radiotherapy, however, suffered from the injury after the treatment.

\section{Methods}

\section{Descriptive study with clinical intervention}

In this study, we examined all Head and Neck Cancer patients before and after radiotherapy, thus found that 148 patients have suffered from middle-ear damage post-treatment. These patients were then divided into two groups: Group A included those with OME or tympanosclerosis who later undergo myringotomy and tympanotomy, and group B consists of those with Eustachian dysfunction who did not require any intervened treatment. The patients in those two groups were examined and monitored for one month after the radiotherapy using otoscopy, audiometry, and tympanometry test.

\section{Results}

In this study, we reported the average age of $148 \mathrm{HNC}$ patients to

*Corresponding author: Nguyen LP, Department of Otorhinolaryngology, Military Medical 103 Hospital, Le Huu Trac Medical Pharmaceutical University, Vietnam, Tel: (+84) 932 681; E-mail: drlongb6@gmail.com 486

Received: October 10, 2018; Accepted: November 01, 2018; Published: November 11, 2018

Citation: Huong LD, Nguyen LP Nguyen HX (2018) Secondary Middleear Damages in Patients with Head and Neck Cancer after Radiotherapy. J Pharmacovigil S4: 002. doi:10.4172/2329-6887.1000S4-002

Copyright: $\odot 2018$ Huong LD, et al. This is an open-access article distributed under the terms of the Creative Commons Attribution License, which permits unrestricted use, distribution, and reproduction in any medium, provided the original author and source are credited. 
be 54.46 years (The youngest was 13 while the oldest was 76 years old). Of the gender population, 125 were male $(84.5 \%)$ while 23 were female (15.5\%) (Table 1). Among patients (72; 48.65\%) who were diagnosed with Nasopharyngeal Cancer (NPC), 27 (18.24\%) were with larynxhypopharynx cancer, $36(24.32 \%)$ with oral cavity cancer, $6(4.05 \%)$ with sino-sinus cancer, and $3(2.70 \%)$ with lympho nodes metastics. Chemoradiotherapy was employed to treat $134 \mathrm{HNC}$ patients while 14 patients were treated with radiation alone. The number of patients who suffered from unilateral and bilateral Eustachian tube dysfunctions after the radiotherapy was found to be 11 and 137, respectively. Among 286 ears of 148 post-irradiation HNC patients, there were 283 damaged middle ears (98.95\%) in which 39 ears were treated by myringotomy and 45 ears by tympanostomy (Table 1). After the radiotherapy, the patients reported that the most common clinical signs were tinnitus (96.59\%) and loss hearing $(96.93 \%)$, followed by an earache $(36.52 \%)$ and ear discharge (9.09\%) (Figure 1).

\begin{tabular}{|c|c|}
\hline Characteristics & Value \\
\hline \multicolumn{2}{|l|}{ Age (years) } \\
\hline Mean & 54.46 \\
\hline Range & $15-76$ \\
\hline \multicolumn{2}{|l|}{ Gender (n/\%) } \\
\hline Male & $125(84.5 \%)$ \\
\hline Female & $23(15.5 \%)$ \\
\hline \multicolumn{2}{|l|}{ Tumor $(n / \%)$} \\
\hline Nasopharyn carcinoma & $72(48.65 \%)$ \\
\hline Tosil & $3(2.03 \%)$ \\
\hline Oral cavity & $36(24.32 \%)$ \\
\hline Larynx - Hypopharynx & $27(18.24 \%)$ \\
\hline Sino - sinus & $6(4.05 \%)$ \\
\hline Lympho nodes & $4(2.70 \%)$ \\
\hline \multicolumn{2}{|l|}{ Chemotherapy $(\mathrm{n} / \%)$} \\
\hline Yes & $134(90.5 \%)$ \\
\hline No & $14(9.5 \%)$ \\
\hline \multicolumn{2}{|l|}{ Eustachian tube dysfunction (n/\%) } \\
\hline Unilateral & $11(7.43 \%)$ \\
\hline Left & $8(5.41 \%)$ \\
\hline Righ & $3(2.02 \%)$ \\
\hline Bilateral & $136(92.57 \%)$ \\
\hline \multicolumn{2}{|l|}{ After radiotherapy $(\mathrm{n} / \%)$} \\
\hline Otitis media with effusion & $53(63.10 \%)$ \\
\hline Tympanocerosis & $31(36.90 \%)$ \\
\hline \multicolumn{2}{|l|}{ Treatments (n/\%) } \\
\hline Myringotomy & $39(46.43 \%)$ \\
\hline Tympanostomy & $45(53.57 \%)$ \\
\hline
\end{tabular}

Table 1: Patient characteristics.
Following the radiotherapy treatment, the patients' eardrum was progressing toward the pathological pathway of Eustachian tube dysfunction. These changes were represented by the color $(54.27 \%$ dull grey eardrum), morphology (54.26\% thick eardrum), mobility (63.48\% less mobile eardrum), and light reflection of the eardrums (97.95\% reduced or lost light reflection) (Table 2). According to the tympanometry classification of Jeger (1975), Handbook of Clinical Impedance Audiometry. New York: American electromedics Corp), we found that the most common was type As tympanometry (59.73\%) while type A was present in only $2.04 \%$ patients (Figure 2). Thus, the total percentage of the pathological middle ear was $97.96 \%$. After the irradiation, several patients suffered from reduced or lost hearing: $75.43 \%$ at $21-40 \mathrm{~dB}$ and $22.53 \%$ at $41-60 \mathrm{~dB}$. We observed a significant improvement in the pure tone audiometry (PTA) and hearing level of the treated patients after myringotomy and tympanostomy. In one month post-myringotomy, the loss hearing at $41-60 \mathrm{~dB}$ was completely cured while the normal hearing increased by $25.64 \%$. Similarly, one month after the tympanostomy treatment, the normal hearing increased by $42.22 \%$. Furthermore, the loss hearing also decreased from $88.89 \%$ to $55.55 \%$ (Table 3). After the myringotomy with 39 ears, the percentage of

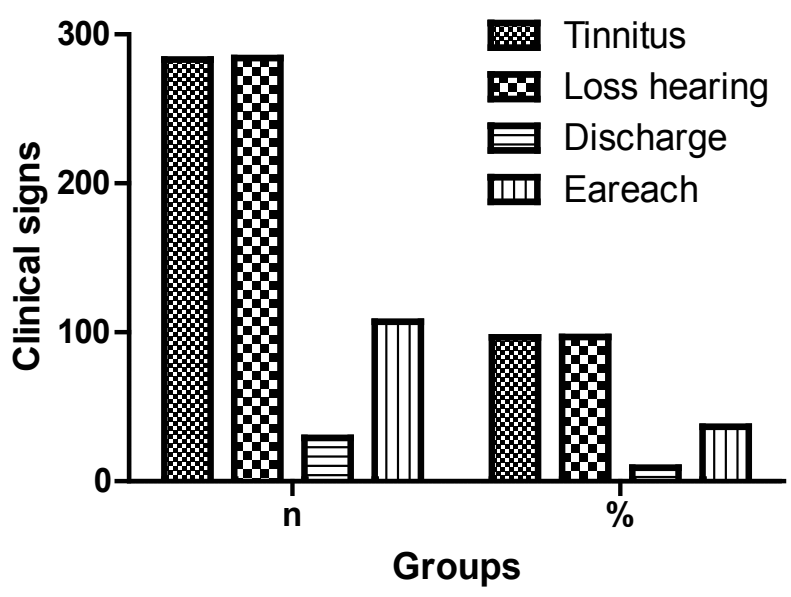

Figure1: Clinical signs.

\begin{tabular}{|c|c|c|c|}
\hline & Symptoms & $\mathbf{n}$ & $\%$ \\
\hline \multirow{4}{*}{ Color } & Normal & 6 & 2.04 \\
\hline & Dull grey & 159 & 54.27 \\
\hline & Yellow & 128 & 43.69 \\
\hline & Total & 293 & 100.00 \\
\hline \multirow{6}{*}{ Morphology } & Normal & 6 & 2.05 \\
\hline & Contracted & 12 & 4.10 \\
\hline & Flat & 159 & 54.27 \\
\hline & Budging & 92 & 31.40 \\
\hline & Reptured & 24 & 8.19 \\
\hline & Total & 293 & 100.00 \\
\hline \multirow{4}{*}{ Mobility } & Normal & 6 & 2.05 \\
\hline & Less mobile & 186 & 63.48 \\
\hline & Immobile & 101 & 34.47 \\
\hline & Total & 293 & 100.00 \\
\hline \multirow{3}{*}{ Light reflection } & Normal & 6 & 2.05 \\
\hline & Reduced/lost & 287 & 97.95 \\
\hline & Total & 293 & 100.00 \\
\hline
\end{tabular}

Table 2: Clinical symptoms. 


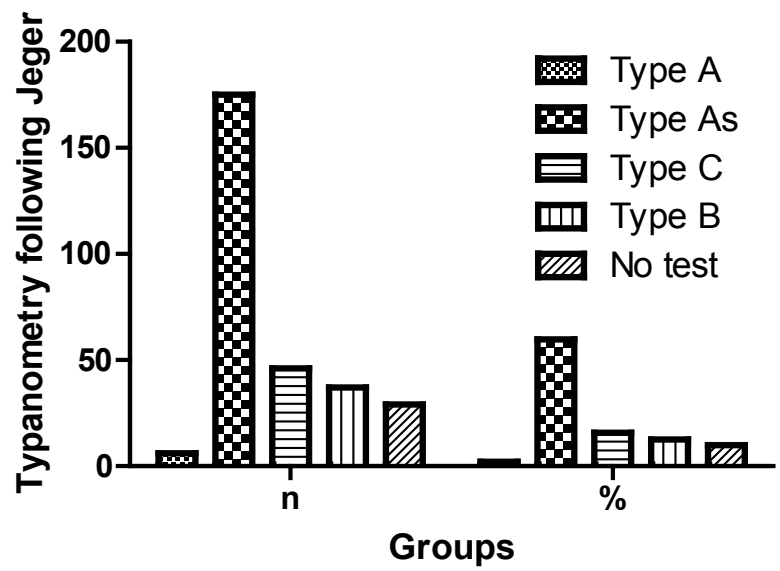

Figure 2: Typanometry in Jeger classification.

\begin{tabular}{|c|c|c|c|}
\hline & $\mathbf{5 2 0} \mathbf{~ d B}$ & $\mathbf{2 1 - 4 0} \mathbf{~ d B}$ & $\mathbf{4 1 - 6 0 ~ d B}$ \\
\hline Myringotomy & & & \\
\hline Before & 0 & $25(64.10 \%)$ & $14(35.90 \%)$ \\
\hline After & $10(25.64 \%)$ & $29(74.36 \%)$ & 0 \\
\hline Tympanostomy & & & \\
\hline Before & 0 & $40(88.89 \%)$ & $5(11.11 \%)$ \\
\hline After & $19(42.22 \%)$ & $25(55.55 \%)$ & $1(2.23 \%)$ \\
\hline
\end{tabular}

Table 3: Audiographies after the treatment by myringotomy and tympanostomy.

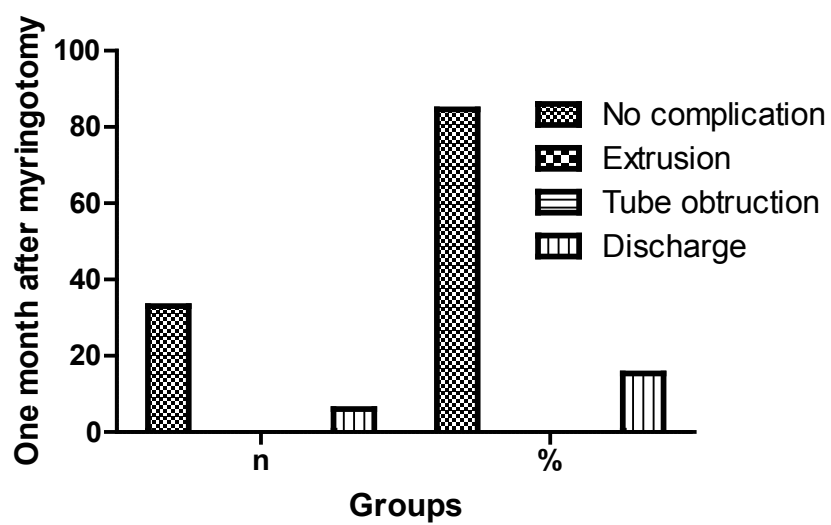

Figure 3: Results after one-month myringotomy

"no complication" and "discharge" was $84.62 \%$ and $15.38 \%$, respectively (Figure 3).

\section{Discussion}

The average age of patients recruited in this study was 54.46 years in which the oldest and youngest were 76 and 13 years old, respectively (Table 1). This observation was consistent with a report from Charlie et al. that on average HNCs patients were 57.9 years of age. Winnie et al. found the age of these patients to be 55.3 years $[5,6]$. The patient gender ratio was around 5.5:1 (male: Female) while males accounted for an estimated $84.5 \%$ of those with HNCs. This result might be attributed to heavy tobacco use and alcohol consumption of males. Furthermore, the risk of HNCs could be increased by several factors including stress, environmental pollution, and low-quality foods. The male: female ratio in our study was markedly lower than that stated by Tsair - Fwu et al. (1 female: 8 to 9 males), however, higher than the ratio reported by
Winnie et al. and Charlie et al. ( 1 female: 1 to 3 males). This difference might be explained by the different objects among the studies. In Vietnam, males have a higher risk of developing HNCs than their female counterparts due to their genes and eating habits (high intake of sauce and salt). Men in the age range from 46 to 65 years are at the highest risk of HNCs. On the other hand, they are expected to make the most substantial contribution to their families and society. Thus, they should be regularly examined, frequently monitored, and sufficiently educated for early detection of HNCs.

In the present study, among the HNCs patients were 72 (48.65\%) with NPC, 27 (18.24\%) with larynx - hypopharynx cancer, 36 (24.32\%) with oral cavity cancer, 6 (4.05\%) with sino - sinus cancer, and $4(2.70 \%)$ with lympho nodes metastics. Interestingly, Winnie and Tsair-Fwu had a similar observation. Our results were also supported by other works (Vu, 2007). However, Charlie revealed that oral cancers were diagnosed in the majority of HNCs patients. This discrepancy might be related to the research location and epidemiology [5-7]. Vietnam is one of the areas with the highest rate of NPC reported in HNCs. In this study, we treated $134 \mathrm{HNCs}$ patients with chemoradiotherapy and 14 patients with only radiotherapy. After radiotherapy, 11 patients suffered from unilateral Eustachian tube dysfunctions while 137 patients coped with bilateral Eustachian tube dysfunction. Among 294 ears of $147 \mathrm{HNC}$ patients were 283 middle ears with damages. We treated 39 ears with myringotomy and 45 ears with tympanostomy. Our study indicated that the most common clinical signs, as well as the most significant alteration after radiotherapy, were tinnitus (96.59\%) and loss hearing (96.93\%). Earache and ear discharge were observed in 36.52\% and $9.09 \%$ of the patients, respectively. The appearance of these signs suggested the abnormal middle ear, following the radiation. Similarly, in the literature tinnitus and loss hearing were also regarded as the most noted complications in the ear. The rate of tinnitus and loss hearing in the present study was considerably higher than the report generated by Winnie et al. in which tinnitus was $6.7 \%$ and loss hearing was $6.0 \%$ of 285 HNCs patients who survived more than one year after radiation treatment [6]. This difference might be attributed to their regimen where the complications were treated early, thus resulted in a decrease in the complication rate. In another study, Fossa et al. found that during radiation $40 \%$ of the patients had acute otitis media while onethird of them advanced towards sudden sensorineural hearing loss. Furthermore, $40 \%$ of the patients were found with clinical signs of OME such as tinnitus, loss hearing, pain ear, echo in the ear, or discharge [8].

Eustachian tube dysfunction post-radiotherapy might be the cause for damages to the eardrum that were represented by the modification in its color ( $54.27 \%$ dull grey eardrum), morphology $(54.27 \%$ flat eardrum), mobility (63.48\% less mobile eardrum), and light reflex (97.95\% less or lost light reflex). According to Winnie and Fossa groups, the eardrum of patients with otitis effusion media also experienced an endoscopic change in the color and mobility. Vu et al. performed an investigation into 187 NPC patients after radiation and reported that the percentage of patients with dull grey eardrum was $22.5 \%$, and with effusion in middle ear was $17.7 \%[6,8,9]$ These results were lower than our observation and might be explained by the difference in the study subjects and evaluation time points.

According to Jeger classification of tympanometry, type As (59.73\%) is the most common tympanometry, following by type A $(2.04 \%)$ Thus, $97.96 \%$ of the patients suffered from the secondary middle ear damage after radiotherapy, which was caused by the pathological and dysfunctional Eustachian tube ventilation. Several research groups have considered tympanometry as the most reliable test to evaluate 
the middle ear conditions. Terese Finitozo and colleagues found the sensitivity of tympanometry and endoscopy in diagnosing diseases in the middle ear to be more than $90 \%$. Low et al. carried out a study on 33 NPC patients before and after radiotherapy; they found a negative pressure in the middle ear post-radiation (ranging from- $215 \mathrm{mmH}_{2} \mathrm{O}$ to $35 \mathrm{mmH}_{2} \mathrm{O}$, the average of-73.1 $\mathrm{mmH}_{2} \mathrm{O}$ ) and two third of the patients with otitis effusion $[10,11] \mathrm{Vu}$ et al. found the percentage of NPC patients with tympanometry type As, C, and B to be $9.4 \%, 12.6 \%$, and $6.7 \%$, respectively. Furthermore, these disorders were caused by the dysfunction of Eustachian tube [9].

After radiotherapy, loss hearing was observed in $75.43 \%$ of patients at $21-40 \mathrm{~dB}$ and in $22.53 \%$ of patients at $41-60 \mathrm{~dB}$. This was similar to the results of Fossa groups that loss hearing was induced by conductive deafness. No matter if being associated with effusion in the middle ear or not, the degree of hearing loss was generally ranging from 25 to 30 $\mathrm{dB}$. According to $\mathrm{Vu}$ et al. loss hearing at a medium level accounted for $49.4 \%$ and at a moderate level for $48.1 \%$. The most significant hearing loss was observed in the range from 31 to $40 \mathrm{~dB}$. Charlie et al. stated that the level of loss hearing depends on the radiation dose; a dose of 60 Gy led to a loss hearing of approximately $25.1 \mathrm{~dB}$ at $8000 \mathrm{~Hz}$ and $6.6 \mathrm{~dB}$ at $1000 \mathrm{~Hz}$. [5,8,9]. We found that after miringotomy and tympanotomy, the pure tone audiometry (PTA) and hearing level of the patients were improved notably. After one-month miringotomy, loss hearing at 41$60 \mathrm{~dB}$ was completely eliminated while normal hearing increased by $25.64 \%$. Similarly, after one-month tympanostomy, the rate of normal hearing increased by $42.22 \%$ while loss hearing at $21-40 \mathrm{~dB}$ markedly decreased from $88.89 \%$ to $55.55 \%$. Our results were consistent with a study from $\mathrm{Vu}$ et al. in which the most significant improvement in PTA was observed at 31-40 dB after miringotomy and at 21-30 dB after tympanostomy [9]. According to Yi-Ho Young and Sheen, ten years after the radiation, the average hearing post-tympanostomy was improved at $500,1000,2000$ và $4000 \mathrm{~Hz}$ from $30,32,35$, and $38 \mathrm{~dB}$ to 17 , 21,22 , and $24 \mathrm{~dB}$, respectively [12]. Among 39 ears after myringotomy, no complication was found in $84.62 \%$ and discharge in $15.38 \%$ of the ears. In this study, we recommended otorrhea after myringotomy to be treated with antibiotic drops, oral antibiotic, and oral anti-histamine. We also noticed scabs granulation tissue and osteoradionecrosis in external acoustic meatus, rhinitis, and sinusitis of the patients after radiotherapy. Thus, the patients should take care of the nose, accessory nasal sinuses, and external acoustic meatus to maintain a clean environment around the Eustachian tube [13-16].

\section{Conclusion}

The most common complication after radiotherapy treatment for head and neck cancers were found to be Eustachian tube dysfunction, especially otitis media with effusion (OME) and tympanosclerosis. Thus, thorough examination and strict monitoring are required to detect those cases with middle ear damages. In this study, we concluded that myringotomy and tympanotomy offered multiple advantages of their simplicity, effectiveness, and patients' compliance. Further investigation is expected to optimize the treatment of irradiation- induced OME and to minimize the secondary injury to the middle ear and Eustachian tube.

\section{Reference}

1. Akazawa K, Doi H, Ohta S, Terada T, Fujiwara M, et al. (2018) Relationship between Eustachian tube dysfunction and otitis media with effusion in radiotherapy patients. J Laryngol Otol 132: 1-6.

2. Kuo CL, Wang MC, Chu CH, Shiao AS (2012) New therapeutic strategy for treating otitis media with effusion in postirradiated nasopharyngeal carcinoma patients. J Chin Med Assoc 75: 329-334.

3. Hsin CH, Chen TH, Liang KL, Tseng HC, Liu WS (2013) Postirradiation otitis media with effusion in nasopharyngeal carcinoma patients treated by intensitymodulated radiotherapy. Laryngoscope 123: 2148-2153.

4. Hsin $\mathrm{CH}$, Chen TH, Young YH, Liu WS (2010) Comparison of otologic complications between intensity-modulated and two-dimensional radiotherapies in nasopharyngeal carcinoma patients. Otolaryngol Head Neck Surg 143: 662 668

5. Pan CC, Eisbruch A, Lee JS, Snorrason RM, Haken RT, et al. (2005) Prospective study of inner ear radiation dose and hearing loss in head - and - neck cancer patients. Int J Radiation Oncology Biol Phys 61: 393-1402.

6. So WK, Choi KC, Chen JM, Chan CW, Chair SY, et al. (2014) Quality of life in head and neck cancer survivors at 1 year after treatment: the mediating role of unmet supportive care needs. Support Care Cancer 22 :2917-26.

7. Lee TF Yeh SA, Chao PJ, Chang L, Chiu CL et al (2015) Normal tissue complication probability modeling for cochlea constraints to avoid causing tinnitus after head and neck intensity-modulated radiation therapy. Radiat oncol 10:194.

8. Jereczek-Fossa BA, Zarowski A, Milani F, Orecchia R (2003) Radiotherapyinduced ear toxicity. Cancer Treat Rev 29: 417-430.

9. Vu P (2007) To study effect of nasopharyn carcinoma and radiotherapy to ventilation function of Eustachian tube, some methodes to repairing, Ph.D thesis, Ha Noi Medical University.

10. Finitzo T, Friel-Patti S, Chinn K, Brown O (1992) Tympanometry and otoscopy prior to myringotomy: Issues in diagnosis of otitis media. Int J Pediatr Otorhinolaryngol 24: 101-110.

11. Low WK, Toh ST, Wee J, Fook-Chong SM, Wang DY (2006) Sensorineura hearing loss after radiotherapy and chemoradiotherapy: A single, blinded, randomized study. J Clin Oncol 24: 1904-1909.

12. Young YH, SHEEN TS (1998) Preservation of tubal function in patients with nasopharyngeal carcinoma, post-irradiation. Acta Otolaryngol 118: 280-283.

13. Xu YD, Ou YK, Zheng YQ, Chen Y, Ji SF (2008) The treatment for postirradiation otitis media with effusion: A study of three methods. Laryngoscope 118: 20402043

14. So WK, Choi KC, Chen JM, Chan CW, Fung OW, et al. (2014) Quality of life in head and neck cancer survivors at 1 year after treatment: The mediating role of unmet supportive care needs. Support Care Cancer 22: 2917-2926.

15. Lee TF, Yeh SA, Chao PJ, Chang L, Chiu CL, et al. (2015) Normal tissue complication probability modeling for cochlea constraints to avoid causing tinnitus after head-and-neck intensity-modulated radiation therapy. Radiat Oncol 10: 194.

16. Liang KL, Su MC, Twu CW, Jiang RS, Lin JC, et al. (2011) Long-term result of management of otitis media with effusion in patients with post-irradiated nasopharyngeal carcinoma. Eur Arch Otorhinolaryngol 268: 213-217. 